\title{
НАПРАВЛЕНИЯ ИСПОЛЬЗОВАНИЯ ПОЗИТИВНОЙ ПСИХОТЕРАПИИ В КОНСУЛЬТАТИВНОМ ПРОЦЕССЕ
}

\section{DIRECTIONS FOR USING POSITIVE PSYCHOTHERAPY IN THE CONSULTATION PROCESS}

\section{G. Barkhoyants}

Summary: The article reveals the theoretical essence of positive psychotherapy, as well as the directions of its use in psychological counseling. The use of techniques and techniques of positive psychotherapy in short-term counseling is justified. The directions of using positive psychotherapy in the framework of personal growth of the client, in crisis situations when emotional burnout occurs, as well as in situations of optimizing family and child-parent relationships are specified.

Keywords: positive psychotherapy, consultation process, psychological counseling, five-step strategy, positive interpretation, personal growth, conflict, current abilities.
Бархояни Галина Владимировна

Соискатель, Кубанский государственный университет alexayhta@mail.ru

Аннотация: В статье раскрывается теоретическая сущность позитивной психотерапии, а также направления ее использования в психологическом консультировании. Обосновано применение техник и приемов позитивной психотерапии в практике краткосрочного консультирования. Конкретизированы направления использования позитивной психотерапии в рамках личностного роста клиента, в кризисных ситуациях при возникновении эмоционального выгорания, а также в ситуациях оптимизации семейных и детско-родительских отношений.

Ключевые слова: позитивная психотерапия, консультативный процесс, психологическое консультирование, пятиступенчатая стратегия, позитивная интерпретация, личностный рост, конфликт, актуальные способности.

психологического консультирования вполне оправдано, так как ее содержание в полной мере соответствует целям данного направления практической психологии, а именно: помощи психически здоровым индивидам в достижении ими целей личностного роста, поиске множества альтернативных решений возникшей проблемы. В широком смысле позитивная психотерапия помогает принять и интегрировать разные качества и личностные характеристики, осознать и позитивно интерпретировать их, выявить скрытые ресурсы и способности и научить самопомощи.

Техники позитивной психотерапии могут с успехом использоваться как в групповом, так и в индивидуальном консультировании. Целью данной статьи является конкретизация направлений использования позитивной психотерапии в консультативном процессе, описание их сущности и специфики применения.

Рассмотрим возможные направления использования:

1. Личностный рост и достижение психологической зрелости. Здесь можно выделить следующие векторы саморазвития:

2. формирование позитивной «Я-концепции» личности, основанной на интеграции всех качеств и свойств, принятие позитивной сущности человека с опорой на его потенциал;

3. обучение навыкам пятиступенчатого самоана- 


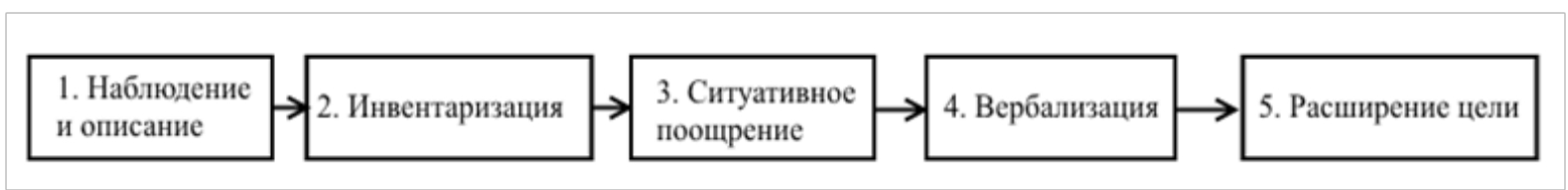

Рис. 1. Ступени пятиступенчатой стратегии [1]

\section{4 сферы жизни}

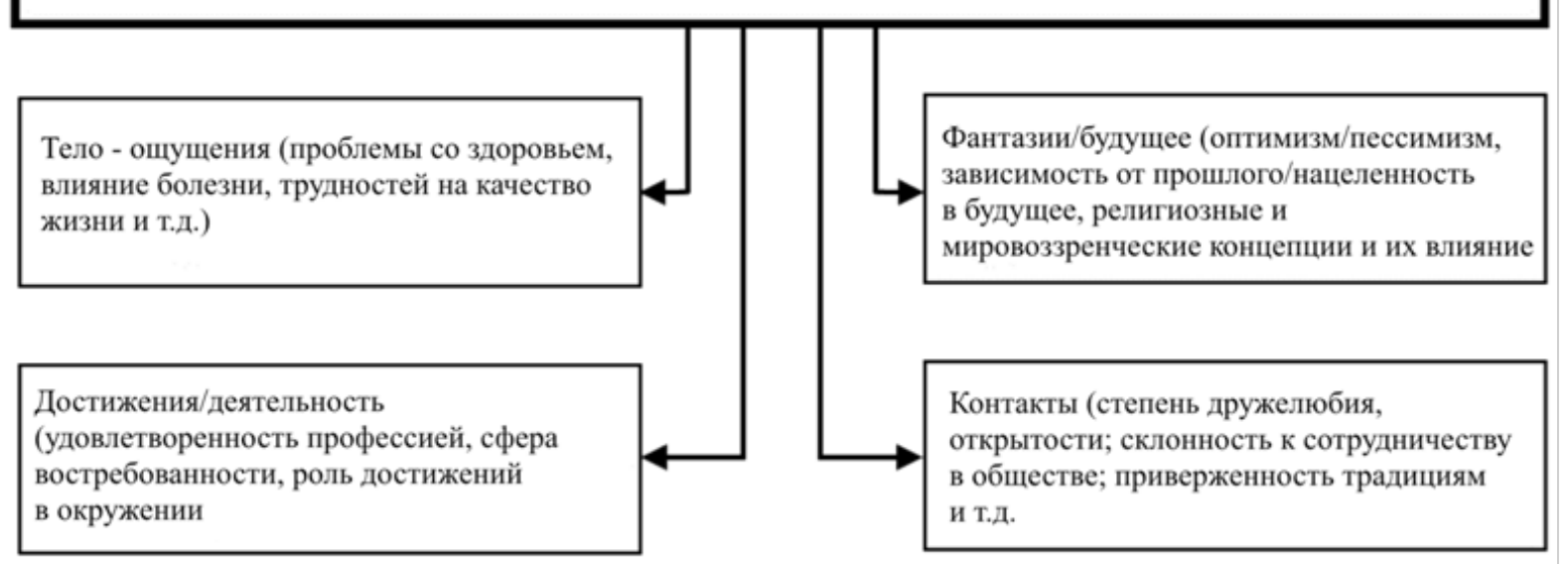

Рис. 2. Исследование основных сфер жизни человека в консультативном процессе [3]

лиза как определенной стратегии самопомощи. Данную модель человек (клиент) сможет использовать при структурировании отношений, изучении особенностей взаимодействия (в том числе в условиях конфликта), при выборе альтернативных подходов в решении проблем.

Так, в рамках развития конфликторазрешающего поведения, клиент совместно с психологом учится:

- выделять причины конфликта, к основным из которых относят: контекст ситуации, индивидуальные психологические реакции, личностные особенности партнеров.

- исследовать возможные последствия на качество жизни;

- критически относится к стереотипам индивидуального поведения в зависимости от сформировавшейся системы отношений (К «Я», «Ты», «Мы» и «Пра-мы») [3].

На рисунке представлены основные этапы (ступени) данной модели, демонстрирующие динамику процесса самоисследования и постепенного выхода из порочного круга проблем, ошибок и конфликтов.

Профилактика эмоционального выгорания, мобилизация способностей к самопомощи за короткий период времени. В решении этой задачи помогает техника гармонизации основных четырех сфер жизни, достижение баланса между ними. Человек учится соблюдать баланс, проводя инвентаризацию, исследование данных сфер (Рисунок 1) с помощью психолога, вопросов проясняющих роль и влияние каждой из них на качество жизни в целом.

Проводя такое исследование в консультативном процессе клиент получает следующие навыки:

1. умения и способы установления контактов с окружающим миром;

2. навыки в применении форм разрешения конфликтов;

3. саморазвитие и повышение осведомленности в оценке качества жизни;

4. расширение способов познавать мир.[3]

Гармонизация семейных отношений, обучение стратегиям сотрудничества на основе формируемых в консультативном процессе партнерских отношений. К работам Н. Пезешкиана относятся «Позитивная семейная психотерапия: семья как терапевт» [5], «Тренинг семейных отношений. 33 и 1 формы партнерства», в содержании которых излагается оригинальная концепция семейных конфликтов, рассматриваются основы формирования партнерских отношений, техники самопомощи.

Важным направлением в консультативной работе являются психосоматические проблемы. В одном из значимых трудов «Психосоматика и позитивная психотера- 
пия» Н. Пезешкиан на примере 40 историй болезней дает представление о физиологических механизмах психологической помощи, что также является неотъемлемой частью психокоррекции в работе с проблемами клиента. В частности психологу важно четко осознавать и прорабатывать «психосоматические симптомы как индикаторы конфликтного или недостаточного переживания»[4], либо как проявление конфликтного переживания клиента. Клиент вместе с психологом учится позитивному подходу к своему заболеванию, включающему в себя:

- учет как индивидуальных, так межкультурных особенностей;

- позитивную интерпретацию симптома;

- разговорную, рациональную терапию.

Еще одно направление использования позитивной психотерапии в консультативном процессе - это оптимизация воспитания детей, развитие педагогической мудрости родителей. В этой связи хотелось бы упомянуть такие труды основателя научной школы, как «Психотерапия повседневной жизни. Тренинг в воспитании партнерства и самопомощи»[1], «Торговец и попугай»[2], «Если ты хочешь иметь то, что никогда не имел, тогда сделай то, чего никогда не делал»[3]. Суть излагаемого подхода в воспитании детей заключается:

- в оптимизации условий для развития базовых, актуальных способностей ребенка: способности к любви и способности к познанию.

- в осознавании и коррекции «издержек» воспитания (гипоопеки или гиперопеки), в чем также хорошо помогают притчи, истории.
- в помощи и осознании влияния религиозных и мировоззренческих факторов, их роли в формировании актуальных конфликтов в детско-родительских отношениях, использовании транскультурального подхода.

Во всех данных направлениях работы с успехом используются истории, притчи, аллегорические рассказы, способствующие изменению образа мыслей. Ведь в консультативном процессе речь идет о расширении представлений человека о самом себе, своих установок и воззрений. Здесь применяются не только логические ходы психолога, но и задействуется фантазия клиента. Для ее пробуждения, для придания наглядности словам психолога в позитивной психотерапии применяют восточные и западные истории. Они представляют собой некие модели, отражающие актуальные для клиента конфликты, возможные варианты поведения в них и последствия определенных выборов. Идентифицируясь с героями притчи, человек легче принимает альтернативные стратегии, испытывает новые переживания, открывающие путь к инсайту.

Таким образом, рассмотрев основные направления использования позитивной психотерапии в консультативном процессе, мы делаем вывод о широком диапазоне возможностей данного подхода в достижении целей личностного роста, коррекции Я-концепции, оптимизации межличностных отношений человека, а также повышении его психолого-педагогической компетентности в целом.

\section{ЛИТЕРАТУРА}

1. Пезешкиан, Н. Психотерапия повседневной жизни. Тренинг в воспитании партнерства и самопомощи: с 250 примерами из практики/ Н. Пезешкиан. Москва: Медицина, 1995. - 335 с.

2. Пезешкиан Н. Торговец и попугай. Восточные истории в психотерапии: учебно-практическое пособие / Н. Пезешкиан.- М.: Академический Проект: Гаудеамус, 2011. - 124 c.

3. Пезешкиан Н. Если ты хочешь иметь то, что никогда не имел, тогда сделай то, чего никогда не делал / Н. Пезешкиан.- М.: Институт позитивной психотерапии, 2005.- $128 \mathrm{c}$.

4. Пезешкиан Н. Психосоматика и позитивная психотерапия / Н. Пезешкиан.- М.: Институт позитивной психотерапии, 2006.- 464 с.

5. Пезешкиан, Н. Позитивная семейная психотерапия: Семья как терапевт: Пер. с англ., нем. / Н. Пезешкиан. - 2-е изд., с изм. - Москва: Культура, 1994. 332 c.

() Бархоянц Галина Владимировна (alexayhta@mail.ru).

Журнал «Современная наука: актуальные проблемы теории и практики» 